\title{
Screening and Counseling for Childhood Obesity: Results from a National Survey
}

\author{
Tracy S. Sesselberg, MA, MPH, Jonathan D. Klein, MD, MPH, Karen G. O'Connor, BS, \\ and Mark S. Johnson, MD, MPH
}

Purpose: To examine family physicians' beliefs and practices about using body mass index (BMI) percentiles to screen for childhood overweight and obesity.

Methods: Surveys about management of childhood overweight were mailed to 1800 American Academy of Family Physician members in 2006.

Results: 729 surveys were returned; 445 were eligible. Most (71\%) members were familiar with BMI guidelines; $41 \%$ were familiar with American Academy of Family Physician recommendations about overweight. Most (78\%) had tools available to calculate BMI; fewer have enough time for overweight screening (55\%), and only $45 \%$ reported computing BMI percentile at most or every well visit for children older than 2. Having an electronic health record increased BMI screening rates. Family physicians felt prepared to discuss weight, but only $43 \%$ believed their counseling was effective and many (55\%) lack community or referral services. Most $(72 \%)$ wanted simple diet and exercise recommendations for patients. Reimbursement for weight-related services is insufficient: $86 \%$ say that patients cannot pay for services not covered by insurance. Factor analysis identified clinician self-efficacy, resources, and reimbursement as factors related to calculating BMI percentiles.

Conclusions: BMI is underutilized by family physicians. Most believe they should try to prevent overweight and have tools to use BMI, but clinicians have few resources available for treatment, have low self-efficacy, and report inadequate reimbursement. (J Am Board Fam Med 2010;23:334-342.)

Keywords: Obesity, Pediatrics, Child, Prevention, Screening, Counseling

Childhood overweight (and obesity) has been recognized as a significant health problem in the United States. The prevalence of overweight among children has increased significantly for the past 20 years: $17 \%$ of children aged 2 to 19 are now considered to be overweight. ${ }^{1}$ Overweight children are at significant risk for many medical conditions, including cardiovascular disease, type 2 diabetes, and psychosocial issues such as lowered self-esteem and depression..$^{2-4}$ An American Academy of Fam-

This article was externally peer reviewed.

Submitted 6 April 2009; revised 8 October 2009; accepted 12 October 2009.

From the Division of Adolescent Medicine, University of Rochester School of Medicine and Dentistry, Rochester, NY (TSS); Department of Research, American Academy of Pediatrics, Elk Grove Village, IL (KGO, JDK); and Department of Family Medicine, University of Medicine and Dentistry, New Jersey Medical School, Newark (MSJ).

Funding: This work was funded by grant no. 053344 from the Robert Wood Johnson Foundation.

Conflict of interest: none declared.

Corresponding author: Jonathan D. Klein, MD, MPH, American Academy of Pediatrics, 141 Northwest Point Boulevard, Elk Grove Village, IL 60007 (E-mail: jklein@ aap.org). ily Physicians (AAFP) 2004 policy statement urged that obesity be considered a chronic disease and treated as such and that diagnosis and treatment be reimbursable. $^{5}$ Continuing Medical Education (CME) training about healthy lifestyles is available on the AAFP website, as are links to CME for the Endocrine Society's guidelines for pediatric obesity, ${ }^{6,7}$ which were sent to AAFP members in September 2008.

Prevention and early identification are key to decreasing the prevalence of overweight. In 2000, the Centers for Disease Control recommended using age- and gender-adjusted body mass index (BMI; $\mathrm{kg} / \mathrm{m}^{2}$ ) to screen for overweight children ages 2 to 19 years old. ${ }^{8,9}$ Monitoring for upward crossing of BMI percentiles may identify children at risk of becoming overweight sooner than traditional plotting of weight for age. In 2003, the American Academy of Pediatrics released a policy statement recommending that providers "calculate and plot BMI (percentiles) once a year in all children and adolescents" as well as to "[u]se change in BMI to identify rate of excessive weight gain rela- 
tive to linear growth."10 The rate at which BMI percentile is measured in practice since publication of the newest guidelines is unknown, and little research has been done on BMI use among family physicians. Although the recommendation to use $\mathrm{BMI}$ to screen for overweight was introduced as early as 1998, ${ }^{11,12}$ subsequent studies have demonstrated that providers who care for children have not fully adopted BMI in the evaluation of overweight children. Barlow et $\mathrm{al}^{13}$ reported in 2002 that only $19 \%$ of pediatricians used BMI. Among North Carolina pediatricians, only 11\% "always" use BMI and 31\% "never" use BMI. ${ }^{14}$ Some believe that they can easily recognize the child or adolescent who is overweight. ${ }^{15}$ More recently, a study in 2 family medicine practices found that $63 \%$ of adult patients had BMI calculated during a well visit. Height and weight were calculated for $95 \%$ of the children, but none had BMI calculated; the authors recommended that family physicians use BMI for age for children and adolescents. ${ }^{16}$ Clinicians rarely document overweight, although they perceive high BMI more seriously than weight and height measures. ${ }^{14}$ When documentation occurs, screening, counseling, and referral rates increase. ${ }^{16,17}$ Another recent study found that pediatricians identified training, time, and resources as barriers to BMI use. ${ }^{18}$ Among family physicians, use of an electronic health record (EHR) significantly increased the use of BMI and increased documentation and treatment of obese (but not overweight) adults. ${ }^{19}$ Few strategies have been found to be effective for treatment of childhood overweight and obesity, although a recent Cochrane Review ${ }^{20}$ concluded that family-based lifestyle interventions can be effective. We conducted this study to obtain baseline data on the prevalence of BMI percentile use in family practice and to determine what modifiable factors may predict or prevent BMI percentile use.

\section{Methods}

We conducted a self-administered survey of family physicians. The survey instrument was modified from a parallel survey of American Academy of Pediatrics members as part of a needs assessment supported by the Robert Wood Johnson Foundation. ${ }^{21}$ The survey was reviewed and approved by the institutional review boards at the University of Rochester and University of Medicine and Den-
tistry-New Jersey Medical School. We purchased a random sample of 1800 family physician members from the AAFP and mailed surveys to each member. Up to 4 reminder letters and duplicate surveys were mailed to nonresponders and reminder telephone calls were made to those who had phone numbers available. When we developed the survey, the terminology for overweight in children was different: "at risk of overweight" and "overweight" were used to describe children who would now be categorized as "overweight" and "obese." 22 The terms used on the survey are used here.

\section{Measures and Analysis}

The survey assessed family physicians' attitudes and practices about prevention, screening, and interventions for overweight; barriers preventing screening and treatment; family physicians' treatment and referral practices; and resources available in the office and community. We compared results by provider demographics, including sex, age, and self-reported clinician BMI, percent of time spent in general family practice, practice type, and practice area (urban, suburban, or rural). We examined the effect of receipt of any CME training about childhood overweight/obesity during the past 3 years on screening and counseling as well as the effect of having an EHR system in the practice.

We conducted $\chi^{2}$ tests and analyses of variance to examine practice characteristics related to BMI percentile use, factors affecting familiarity with guidelines, and whether familiarity affected practices and attitudes related to overweight and use of BMI percentile. We used principal components factor analysis ${ }^{23}$ to identify underlying mechanisms driving physicians' responses on the series of questions related to attitudes affecting screening and treatment practices for overweight children and adolescents. Data were double entered into and cleaned using Microsoft Access (Microsoft, Redmond, WA). All analyses were conducted using SPSS software (SPSS, Inc., Chicago, IL).

\section{Results}

\section{Demographics and Practice Characteristics}

We received 729 responses (41\%) after 5 mailings. Of these, 284 were from respondents who either did not provide preventive care to children, were retired, had incorrect addresses, or were not cur- 
Table 1. Respondent Demographics and Practice Characteristics $(\mathrm{n}=455)$

\begin{tabular}{|c|c|}
\hline & n (\%) \\
\hline \multicolumn{2}{|l|}{ Gender } \\
\hline Male & $255(59)$ \\
\hline Female & $180(41)$ \\
\hline \multicolumn{2}{|l|}{ BMI } \\
\hline Underweight & $7(2)$ \\
\hline Normal weight & $234(57)$ \\
\hline Overweight & $134(32)$ \\
\hline Obese & $38(9)$ \\
\hline \multicolumn{2}{|l|}{ Specialty } \\
\hline General practitioner & $412(96)$ \\
\hline Specialist & $17(4)$ \\
\hline \multicolumn{2}{|l|}{ Primary practice setting } \\
\hline Small family practice (solo or 2 physician) & $94(22)$ \\
\hline $\begin{array}{l}\text { Large family practice/multispecialty group/ } \\
\text { HMO }\end{array}$ & $229(53)$ \\
\hline $\begin{array}{l}\text { Med School/hospital/clinic/community } \\
\text { health center }\end{array}$ & $95(22)$ \\
\hline Other & $13(3)$ \\
\hline \multicolumn{2}{|l|}{ Primary practice/position area } \\
\hline Rural & $129(30)$ \\
\hline Suburban & $170(39)$ \\
\hline Urban & $135(31)$ \\
\hline Use EHR & $175(42)$ \\
\hline \multicolumn{2}{|l|}{$\begin{array}{l}\text { CME or training in childhood/adolescent } \\
\text { overweight } \leq 3 \text { years }\end{array}$} \\
\hline Yes & $180(42)$ \\
\hline No & $253(58)$ \\
\hline Participate in PBRN & $77(17)$ \\
\hline
\end{tabular}

BMI, body mass index; HMO, health maintenance organization; EHR, electronic health record; CME, continuing medical education; PBRN, practice-based research network.

Note: $\mathrm{n}$ varies due to missing data.

rently in practice and therefore were not eligible; this resulted in a final usable sample of 445 completed surveys. Demographics and practice characteristics are shown in Table 1. Fifty-nine percent of respondents were men. The mean age was 44 years. Of note, $41 \%$ of respondents were overweight or obese. Practice locations were 31\% urban, 39\% suburban, and $30 \%$ rural. Forty-two percent use EHRs, $42 \%$ report participation in CME about childhood obesity during the last 3 years, and $17 \%$ participate in practice-based research networks. Respondents' estimates of the prevalence of childhood obesity in their practice ranged from $1 \%$ to 75\% (mean, 26\%). American Family Physician was the most frequently cited source of information about childhood obesity (65\% used this source).
Table 2. Family Physicians' Practices during Children's Well Visits $(n=445)$

\begin{tabular}{|c|c|}
\hline & $\mathrm{n}(\%)$ \\
\hline $\begin{array}{l}\text { Measure height and weight during most or every } \\
\text { visit }\end{array}$ & $422(99)$ \\
\hline \multicolumn{2}{|l|}{$\begin{array}{l}\text { Visually assess for overweight for children }>2 \\
\text { years old }\end{array}$} \\
\hline During every well visit & $329(76)$ \\
\hline During most well visits & $96(22)$ \\
\hline \multicolumn{2}{|l|}{ Compute BMI for children $>2$ years old } \\
\hline During most or every well visit & $195(45)$ \\
\hline During some well visits & $130(30)$ \\
\hline Never or rarely & $41(10)$ \\
\hline \multicolumn{2}{|l|}{ Plot BMI for children $>2$ years old } \\
\hline During most or every well visit & $132(31)$ \\
\hline During some well visits & $83(20)$ \\
\hline Never or rarely & $111(26)$ \\
\hline \multicolumn{2}{|l|}{ Use of BMI calculation tools } \\
\hline BMI wheel & $140(36)$ \\
\hline BMI calculator & $117(30)$ \\
\hline EHR & $111(29)$ \\
\hline PDA & $99(26)$ \\
\hline CDC BMI table/chart & $77(20)$ \\
\hline Wall chart & $61(16)$ \\
\hline Handheld calculator & $21(5)$ \\
\hline \multicolumn{2}{|l|}{ Topics discussed with all patients } \\
\hline Breastfeeding & $370(86)$ \\
\hline Physical activity & $367(84)$ \\
\hline 5-a-day fruits and vegetables & $346(80)$ \\
\hline Screen time & $290(67)$ \\
\hline Sugar-sweetened beverages & $271(63)$ \\
\hline Snacks & $209(48)$ \\
\hline Fast food/dining out & $174(40)$ \\
\hline Food pyramid & $91(21)$ \\
\hline
\end{tabular}

BMI, body mass index; EHR, electronic health record; PDA, personal digital assistant; CDC, Centers for Disease Control and Prevention.

Note: $\mathrm{n}$ varies due to missing data.

\section{Routine Practices during Children's Well Visits}

Almost all respondents plot height and weight during most or every well visit for children younger than age 2 (Table 2). Fewer (45\%) compute BMI percentile during most or every visit for children older than the age of 2 ; an additional $30 \%$ of respondents reported that they compute BMI percentile during some visits. Respondents computed BMI percentile using BMI wheels (36\%), BMI calculators (30\%), and EHRs (29\%). Most (86\%) reported routinely discussing breastfeeding, physical activity (84\%), and 5-a-day fruit and vegetable consumption $(80 \%)$. Fewer routinely discussed time spent using television, computers, and video games 
(67\%), sugar-sweetened beverages (63\%), snacks (48\%), fast food/dining out (40\%), and the food pyramid (21\%).

\section{Attitudes and Perceptions Toward Managing Childhood Obesity}

Family physicians have differing opinions about overweight prevention as distinct from overweight treatment. Approximately half (54\%) believe there is evidence that physicians can prevent overweight and almost all (94\%) think that family physicians should address childhood overweight. However, $44 \%$ believe that schools should be responsible for screening and $17 \%$ believe that overweight is better addressed in community programs. Many (71\%) are familiar with guidelines for BMI screening but only $41 \%$ are familiar with AAFP recommendations about prevention and treatment of childhood overweight; $63 \%$ believe that many families are not familiar with BMI. Half (55\%) reported having adequate time during well visits to screen for overweight, and $78 \%$ report having tools available to calculate BMI percentile.

Almost all (91\%) reported that they were interested in addressing overweight among children; fewer (46\%) say that families want it discussed. Although 84\% reported feeling prepared to counsel families and $89 \%$ felt comfortable counseling and were not worried about offending families by discussing weight, only $43 \%$ felt that their counseling was somewhat or very effective, and fewer (26\%) felt that there were good treatment options. Many felt that there was inadequate time during visits for counseling about weight issues (61\%), that dietitian/weight management services are helpful $(62 \%)$, and that these services are helpful to their patients $(50 \%)$, but more $(72 \%)$ believed that simple diet and exercise recommendations would also help them with their patients.

Despite providers' interest and preparedness to address overweight and beliefs that it should be addressed, 55\% reported a lack of adequate services/resources in their practice area to which they could refer patients, although $27 \%$ reported having a dietitian or nutritionist in their practice. Reimbursement associated with overweight counseling was problematic as well: $63 \%$ of respondents were unfamiliar with billing codes for overweight, few (15\%) were able to bill separately from well visits for overweight counseling, $47 \%$ feel that there is insufficient reimbursement for overweight counsel- ing and treatment, many report that weight management $(72 \%)$ and dietitian (58\%) services are not covered by insurance, and $86 \%$ say that their patients are not able to pay for services that are not covered by insurance. In addition, nearly half (48.8\%) believe that overweight physicians lack credibility when counseling patients about overweight; however, this was not significantly correlated with the provider's own BMI.

Providers who had participated in obesity-related CME were significantly more likely to agree with the statement, "I am familiar with BMI recommendations" (on a scale of 1 to 5 , with 1 being strongly disagree and 5 being strongly agree) than were providers who had not had obesity-related CME (2.36 vs $2.17 ; P<.001)$. Providers who were more familiar with guidelines were also more likely to be using BMI percentile, felt more prepared and comfortable counseling about overweight, and felt their counseling about overweight prevention and management was more effective. Family physicians who used an EHR were significantly more likely to report computing BMI percentile during most or all well visits compared with providers who did not use EHRs (59\% vs 33\%; $\left.\chi^{2}, 27.176 ; P<.001\right)$.

\section{Factors Associated with Use of BMI Percentiles}

Factor analysis identified one strong factor and 2 weaker factors ("self-efficacy," "reimbursement," and "resources"). Varimax and quartimax rotations did not yield simplified solutions or clearer factors. Survey questions that had loading scores of $>0.4$ on the factors, their eigenvalues, and the mean scores of each question are shown in Table 3. Scree plots also were examined during the interpretation of the data. The strongest factor related to selfefficacy and providers' feelings that they can or cannot prevent overweight, and on the effectiveness of their counseling. This "self-efficacy" factor explained $17 \%$ of the variation in response to whether BMI percentile is used. The "reimbursement" factor (explaining 6\% of the variation) relates to reimbursement and insurance items, including uncovered dietitian and weight-management services and patients' inability to pay for services that are not covered by insurance. The third factor included items related to tools and insurance; this "resources" factor explained $5 \%$ of the variation. A fourth weak factor was identified, which consisted of 3 variables that did not have a clear relationship, and 


\begin{tabular}{|c|c|c|c|c|c|}
\hline Questions & $\begin{array}{c}\text { Mean score }(\mathrm{SD}) \\
(1=\text { strongly disagree } \\
5=\text { strongly agree })\end{array}$ & $\begin{array}{l}\text { Factor } 1 * \\
\text { "Self-efficacy" }\end{array}$ & $\begin{array}{l}\text { Factor } 2^{\dagger} \\
\text { "Reimbursement" }\end{array}$ & $\begin{array}{l}\text { Factor } 3^{\ddagger} \\
\text { "Resources" }\end{array}$ & Factor 4 \\
\hline Overweight counseling is not effective. & $2.40(0.949)$ & 0.732 & & & \\
\hline $\begin{array}{l}\text { There is little family physicians can do to treat/ } \\
\text { manage overweight. }\end{array}$ & $2.28(0.993)$ & 0.720 & & & \\
\hline $\begin{array}{l}\text { How effective is your counseling about } \\
\text { overweight management? }\end{array}$ & $2.38(0.690)^{\|}$ & -0.713 & & & \\
\hline $\begin{array}{l}\text { How effective is your counseling about } \\
\text { prevention of obesity? }\end{array}$ & $2.35(0.662)^{\|}$ & -0.687 & & & \\
\hline $\begin{array}{l}\text { There is no evidence physicians can prevent } \\
\text { overweight. }\end{array}$ & $2.43(1.039)$ & 0.661 & & & \\
\hline $\begin{array}{l}\text { Family physicians can help prevent childhood } \\
\text { overweight. }\end{array}$ & $3.94(0.970)$ & -0.660 & & & \\
\hline I don't think screening will make a difference. & $2.10(1.011)$ & 0.608 & & & \\
\hline There are effective means of treating overweight. & $3.17(0.999)$ & -0.581 & & & \\
\hline $\begin{array}{l}\text { There are good treatment options for } \\
\text { overweight. }\end{array}$ & $2.76(1.096)$ & -0.546 & & & \\
\hline My patients do not find these services helpful. & $2.59(0.975)$ & 0.540 & & & \\
\hline $\begin{array}{l}\text { I don't find dietitian/weight-management services } \\
\text { helpful. }\end{array}$ & $2.28(0.993)$ & 0.539 & & & \\
\hline $\begin{array}{l}\text { How comfortable do you feel discussing } \\
\text { overweight with overweight patients and their } \\
\text { parents? }\end{array}$ & $3.28(0.692)$ & -0.458 & & & 0.421 \\
\hline $\begin{array}{l}\text { I am not interested in addressing overweight } \\
\text { prevention/management. }\end{array}$ & $1.62(0.763)$ & 0.448 & & & \\
\hline $\begin{array}{l}\text { Family physicians should address childhood } \\
\text { overweight during well-child visits. }\end{array}$ & $4.55(0.707)$ & -0.415 & & & \\
\hline $\begin{array}{l}\text { How well prepared do you feel you are to } \\
\text { counsel patients and their parents about } \\
\text { overweight? }\end{array}$ & $3.06(0.674)$ & -0.454 & & & 0.513 \\
\hline $\begin{array}{l}\text { The AAFP recommendations on overweight } \\
\text { screening are easy to follow. }\end{array}$ & $3.30(0.686)$ & -0.400 & & & \\
\hline $\begin{array}{l}\text { Weight management programs are not covered } \\
\text { by insurance. }\end{array}$ & $3.95(0.939)$ & & 0.575 & -0.420 & \\
\hline Dietitian services are not covered by insurance. & $3.60(1.11)$ & & 0.687 & & \\
\hline $\begin{array}{l}\text { Many of my patients are not able to pay for } \\
\text { uncovered services. }\end{array}$ & $4.28(0.942)$ & & 0.475 & & \\
\hline $\begin{array}{l}\text { There is a lack of tools to assist with BMI } \\
\text { calculations. }\end{array}$ & $1.87(0.985)$ & & & 0.537 & \\
\hline $\begin{array}{l}\text { It is more important to reduce fast food/soft } \\
\text { drink availability in the community and at } \\
\text { home than to counsel about overweight. }\end{array}$ & $3.16(1.197)$ & & & & 0.426 \\
\hline $\begin{array}{l}\text { I do not want to offend families by talking about } \\
\text { weight. }\end{array}$ & $2.04(1.019)$ & 0.432 & & & \\
\hline Variance explained (\%) & & 17.3 & 5.74 & 5.07 & 5.071 \\
\hline
\end{tabular}

*Eigenvalue of 7.439 .

${ }^{\dagger}$ Eigenvalue of 2.468 .

${ }^{\ddagger}$ Eigenvalue of 2.181 .

${ }^{\S}$ Eigenvalue of 1.927 .

4-point scale.

AAFP, American Academy of Family Physicians; BMI, body mass index.

9 other components were identified that had eigenvalues $>1.0$. However, these were not considered factors because they were generally single variables and explained little variation in BMI percentile use.

\section{Discussion}

Family physicians believe that they can and should address prevention of overweight among children, but some physicians report low self-efficacy and 
significant barriers to treatment. Most family physicians in this survey were familiar with BMI recommendations, half assessed BMI percentile during most or every well visit, and most felt very prepared to screen and counsel patients and families. However, most physicians identified difficulties with providing counseling about overweight. Many of these barriers were at the practice level and some were modifiable in the short or long term. Insufficient time during well visits for counseling, a lack of available referral services, and factors associated with reimbursement are not immediately modifiable, but providers can use effective, brief counseling techniques with parents and patients in the meantime. For example, the 5-2-1-0 screening form developed by the Maine Youth Overweight Collaborative has been found to be an effective and rapid tool for assessment of risk factors related to overweight and obesity. ${ }^{24}$ Similarly, the strategies and tools used by Envision New Mexico $^{25}$ and Northern California Kaiser Permanente's Kids in Dynamic Shape initiatives ${ }^{26}$ are able to be integrated into practice to address obesity risk and prevention.

Our finding that participation in CME about obesity increased familiarity with BMI guidelines was not surprising, but it validates the need for well-planned CME on this topic. Educating physicians about care guidelines and current recommendations is vitally important, especially as guidelines change. Less than half of our sample had received CME about childhood and adolescent overweight during the previous 3 years. Approximately half the providers in our sample felt that they did not have enough time for screening and counseling. CME could provide guidance on how to integrate screening into preventive care visits, and how to provide simple diet and exercise recommendations to give patients and families, thus improving the quality of clinical interventions for children and their families.

Familiarity with guidelines, however, is only one step in implementing BMI percentile screening. Practice characteristics may affect whether or not BMI screening happens during well visits. Physicians who have EHRs were far more likely to report using BMI percentile, and use of an EHR is a modifiable factor. BMI percentile calculations are automatic in many EHR systems and this reduces the time needed for calculation. Increased use of EHR systems will probably increase the proportion of patients who have BMI percentile calculated during well visits, although whether this results in more time for counseling remains to be seen. Adams et $\mathrm{al}^{27}$ also found that implementation of an EHR increased screening for health risk factors and that office systems are effective means of increasing preventive services. ${ }^{28}$ Thus, an EHR with screening questions about weight should help increase screening for this problem.

We identified self-efficacy, reimbursement, and resource factors related to providers' attitudes about BMI screening and counseling about overweight. The strongest factor was related to providers' self-efficacy (whether providers feel that their counseling is effective). Low self-efficacy can lead to lack of adherence to practice guidelines ${ }^{29}$; CME can include strategies to make such counseling more effective. Educational and practice change interventions have been shown to improve preventive services delivery for adolescents through increased clinician self-efficacy ${ }^{30}$ and can also include information about billing codes and reimbursement. The Robert Wood Johnson Foundation has identified elements of an ideal CME program for obesity: nutrition, physical activity, behavior change, educational value, practicality in providers' settings, and efficacy. ${ }^{31}$ Ensuring that all these are incorporated may further enhance the effectiveness of training on clinician practice. Provision of quality care within a "medical home" and community resource development guided by the chronic care model also has the potential to improve access to the resources needed for obesity treatment. ${ }^{32}$

Family physicians care for one third of the children in the United States, especially poorer children and those residing in rural areas. ${ }^{33}$ Family physicians are in a unique position to assist all members of the family with overweight prevention and treatment. ${ }^{34,35}$ This is especially important in the context of screening and counseling for childhood obesity because care for this chronic disease by definition includes family interventions. However, improved prevention may require specific investments in practice systems for effective change to be implemented. ${ }^{36}$

Although family physicians wanted simple diet and exercise recommendations for their patients, they recognized that these may not be enough. Most family physicians in our sample felt that dietitian/weight-management services are helpful to have available and that they are helpful to their 
patients. However, more than half reported a lack of adequate services available for their patients. Even though a third had a dietitian or nutritionist in their practice, reimbursement issues remained a barrier to patients receiving these services.

The family physicians in our sample believed that they had a responsibility to screen and counsel patients on weight management issues, but many also believed that the communities and/or schools should also be responsible and that overweight is better addressed in community programs. Collaboration between family physicians and communities, including schools, to communicate the need to reduce fast food and soft drink availability/consumption and to increase physical activity could enhance the counseling done during well visits. The AAFP has published a policy statement regarding healthy eating in schools, ${ }^{37}$ and one study has examined the ways in which linkages between primary care practices and community resources could be of benefit as well as lessen the burden on the US health care system; infrastructure support and communication systems were identified as crucial to creating and sustaining such linkages. ${ }^{38}$

Limitations of our study included a possible response bias; physicians who had a stronger interest in childhood overweight may have been more likely to return the survey. Our survey was limited to practicing AAFP members and we had a relatively low response rate. Little is known about the nonrespondents. Therefore, the survey data may not be generalizable to the population of family practitioners in the United States. However, it is likely that those who completed the survey were more interested in or attentive to childhood obesity issues, and thus it is likely that our findings provide an optimistic view of the practices of all family practitioners. Actual screening rates in practice are likely to be lower than those reported here. In addition, there may be a social desirability bias present, where providers overestimate the amount of screening and counseling they do. Family physicians in our sample were slightly younger (44 vs 46 years) and more likely to be women ( $41 \%$ vs $35 \%$ percent) than all active AAFP members. ${ }^{39}$ Although these factors may not affect clinical practice, respondents in our sample were also more likely to practice in rural locations than the overall AAFP population ( $30 \%$ in our sample vs $21 \%$ of AAFP members overall) (American Academy of Family Physicians, AAFP Member Relations and
Marketing Research, personal communication, April 2, 2009). Thus, our results may not fully generalize to all family physicians. Lastly, our data were collected in 2006. We recognize that family practitioners' attitudes and behaviors may have changed since the data were collected; however, this survey was intended to provide baseline data on this topic, allowing assessment of improvement or change related to this important topic as strategies to address the obesity epidemic are implemented in the care system and in our communities.

Family physicians report being actively involved in the assessment and management of childhood overweight but lack self-efficacy and identify barriers to treatment. Many report wanting simple guidelines for treating this important problem. Obesity CME is associated with better adherence to current guidelines, and EHRs serve as reminders and documentation for BMI screening and counseling, potentially improving the quality of care. Despite new guidelines for the screening and treatment of childhood overweight, more research into the implementation of effective treatment in practice is needed.

The authors thank C. Tracy Orleans and Terry Bazzare for their advice and guidance in developing our survey instruments.

\section{References}

1. Ogden CL, Carroll MD, Curtin LR, McDowell MA, Tabak CJ, Flegal KM. Prevalence of overweight and obesity in the United States, 1999-2004. JAMA 2006;295:1549-55.

2. Williams CL, Hayman LL, Daniels SR, et al. Cardiovascular health in childhood: a statement for health professionals from the Committee on Atherosclerosis, Hypertension, and Obesity in the Young (AHOY) of the Council on Cardiovascular Disease in the Young, American Heart Association. Circulation 2002;106:143-60.

3. Steinberger J, Daniels SR. Obesity, insulin resistance, diabetes, and cardiovascular risk in children: an American Heart Association scientific statement. Circulation 2003;107:1448-53.

4. Dietz WH, Robinson TN. Clinical practice. Overweight children and adolescents. $\mathrm{N}$ Engl J Med 2005;352:2100-9.

5. American Academy of Family Physicians. Policy Statement on Overweight and Obesity. 2004. Available at: http://www.aafp.org/online/en/home/policy/ policies/o/obesityandoverweight.html. Accessed 9 March 2009.

6. American Academy of Family Physicians. Be active, 
eat smart, feel good: a family-centered approach to healthy lifestyles. CME Bulletin 2006;5:1-10.

7. August GP, Caprio S, Fennoy I, et al. Prevention and treatment of pediatric obesity: an endocrine society clinical practice guideline based on expert opinion. J Clin Endocrinol Metab 2008;93:4576-99.

8. Centers for Disease Control. 2000 CDC Growth Charts: United States. Available at: http://www.cdc. gov/GROWTHcharts/. Accessed 9 March 2009.

9. Kuczmarski RJ, Ogden CL, Guo SS, et al. 2000 CDC growth charts for the United States: methods and development. Vital Health Statistics 2002;11:1190.

10. Krebs NF, Jacobsen MS, American Academy of Pediatrics Committee on Nutrition. Prevention of pediatric overweight and obesity. Pediatrics 2003;112: 424-30.

11. Dietz WH, Robinson TN. Use of the body mass index (BMI) as a measure of overweight in children and adolescents. J Pediatr 1998;132:191-3.

12. Pietrobelli A, Faith MS, Allison DB, Gallagher D, Chiumello G, Heymsfield SB. Body mass index as a measure of adiposity among children and adolescents: a validation study. J Pediatr 1998;132:204-10.

13. Barlow SE, Dietz WH, Klish WJ, Trowbridge FL. Medical evaluation of overweight children and adolescents: reports from pediatricians, pediatric nurse practitioners, and registered dietitians. Pediatrics 2002;110(1 pt 2):222-8.

14. Perrin EM, Flower KB, Ammerman AS. Body mass index charts: useful yet underused. J Pediatr 2004; 114:455-60.

15. Rivara FP, Whitaker R, Sherman PM, Cuttler L. Influencing the childhood behaviors that lead to obesity: role of the pediatrician and health care professional. Arch Pediatr Adolesc Med 2003;157:71920.

16. Boardley D, Sherman C, Ambrosetti L, Lewis J. Obesity evaluation and intervention during family medicine well visits. J Am Board Fam Med 2007;20: 252-7.

17. O'Brien SH, Holubkov R, Reis EC. Identification, evaluation, and management of obesity in an academic primary care center. Pediatrics 2004;114: e154-9.

18. Klein JD, Sesselberg TS, O'Connor KG, et al. Childhood obesity practices of US pediatricians in 2006. Presented at the Pediatric Academic Societies' Annual Meeting, May 2007.

19. Benson L, Baer HJ, Kaelber DC. Trends in the diagnosis of overweight and obesity in children and adolescents: 1999-2007. Pediatrics 2009;123:e153-8.

20. Oude LH, Baur L, Jansen H, et al. Interventions for treating obesity in children. Cochrane Database Syst Rev 2009;(1):CD001872.

21. Klein JD, Sesselberg TS, Johnson MS, O'Connor KG, Cook S, Coon M, Homer C, Krebs N, Washington R. Adoption of body mass index guidelines for screening and counseling in pediatric practice. Pediatrics 2010;125:265-72.

22. Centers for Disease Control and Prevention. Defining Childhood Overweight and Obesity. Available at http://www.cdc.gov/obesity/childhood/defining.html. Accessed 9 March 2009.

23. Cody RP, Smith JK. Applied statistics and the SAS programming language. Fourth edition. Upper Saddle River (NJ): Prentice Hall; 1997.

24. Polacsek M. The Maine Youth Overweight Collaborative final report. Available at http://www.maineaap. org/documents/FinalReport.pdf. Accessed 10 September 2008 .

25. Envision New Mexico. Overweight prevention and management: tools. Available at http://www. envisionnm.org/tools_resources.html\#owp. Accessed 29 July 2009.

26. Lam DP, Robinson-Frank E. Kaiser Permanente Kids in Dynamic Shape (KP KIDS): a parent-child program to tackle childhood obesity. Presented at the 134th Annual Meeting and Exposition of the American Public Health Association, November 4-8, 2006.

27. Adams WG, Mann AM, Bauchner H. Use of an electronic medical record improves the quality of urban pediatric primary care. Pediatrics 2003;111: 626-32.

28. Bordley WC, Margolis PA, Stuart J, Lannon C, Keyes L. Improving preventive service delivery through office systems. Pediatrics 2001;108:E41.

29. Cabana MD, Rand CS, Powe NR, et al. Why don't physicians follow clinical practice guidelines? A framework for improvement. JAMA 1999;282:1458-65.

30. Ozer EM, Adams SH, Lustig JL, et al. Increasing the screening and counseling of adolescents for risky health behaviors: a primary care intervention. Pediatrics 2005;115:960-8.

31. Robert Wood Johnson Foundation, College of Public Health, University of Arkansas for Medical Sciences. Childhood obesity. Continuing provider education of obesity: a panel review of existing programs. Available at http://www.rwjf.org/childhoodobesity/ product.jsp?id=14242. Accessed 17 October 2007.

32. Whitlock EP, Williams SB, Gold R, Smith PR, Shipman SA. Screening and interventions for childhood overweight: a summary of evidence for the US Preventive Services Task Force. Pediatrics 2005;116: e125-44.

33. Phillips RL Jr, Bazemore AW, Dodoo MS, Shipman SA, Green LA. Family physicians in the child health care workforce: opportunities for collaboration in improving the health of children. Pediatrics 2006; 118:1200-6.

34. Flocke SA, Goodwin MA, Stange KC. The effect of a secondary patient on the family practice visit. J Fam Pract 1998;46:429-34. 
35. Orzano AJ, Gregory PM, Nutting PA, Werner JJ, Flocke SA, Stange KC. Care of the secondary patient in family practice. A report from the Ambulatory Sentinel Practice Network. J Fam Pract 2001;50: 113-6.

36. Dodoo MS, Lesser LI, Phillips RL Jr, Bazemore AW, Petterson SM, Xierali I. Changing patient health-risk behavior requires new investment in primary care. Am Fam Physician 2008;78:924.

37. American Academy of Family Physicians. AAFP policy statement: healthy eating in schools. Available at http://www.aafp.org/online/en/home/policy/policies/ h/healthyeatinginschools.html. Accessed 27 January 2009.

38. Etz RS, Cohen DJ, Woolf SH, et al. Bridging primary care practices and communities to promote healthy behaviors. Am J Prev Med 2008;35(5 Suppl): S390-7.

39. American Academy of Family Physicians. Facts about family medicine. Table 3. Percentage of AAFP members by selected characteristics, December 31 , 2007. Available at http://www.aafp.org/online/en/ home/aboutus/specialty/facts/3.html. Accessed 20 January 2009. 